http://www.jfas.info

\title{
POWER LOSS ESTIMATION DUE TO DIFFERENCE TRANSFORMER TAP CHANGER POSITION AT INTERFACE
}

\author{
M. M. Hussain ${ }^{1,}$, Z. Zakaria ${ }^{2}$ and Z. I. Rizman ${ }^{3}$, M. A. M. Yasin ${ }^{4}$ \\ ${ }^{1}$ Faculty of Electrical Engineering, UniversitiTeknologi MARA, 81750 PasirGudang, Johor, \\ Malaysia \\ ${ }^{2}$ Faculty of Electrical Engineering, UniversitiTeknologi MARA, 40450 Shah Alam, Selangor, \\ Malaysia \\ ${ }^{3}$ Faculty of Electrical Engineering, UniversitiTeknologi MARA, 23000 Dungun, Terengganu, \\ Malaysia \\ ${ }^{4}$ Distribution Network Operation, TenagaNasionalBerhad, Malaysia
}

Published online: 10 September 2017

\begin{abstract}
This paper presents a method to reduce the power loss during transmitting energy with different transformer setting at distribution area. Many engineers are not conscious that the transformer tap setting may affect high power loss during transmitting process. By controlling the tap changing, the system can avoid voltage unbalanced on distribution system. This research demonstrated through numerical studies using Power System Simulation for Engineering (PSS $\left.{ }^{\mathrm{TM}} \mathrm{E}\right)$ Software and Python Programming. The Python programming is to generate the load profile for time series by repetitively running the system in 24-hours for every minute. It is taking about 1440 times per day. This load profile is auto generate using 69 test bus system. The integrated simulation systems were simulated for different transformer tap position at 1.0 p.u and tap position at optimal.
\end{abstract}

Author Correspondence, e-mail: mashitah1116@johor.uitm.edu.my

doi: http://dx.doi.org/10.4314/jfas.v9i3s.53 
Keywords: electrical distribution system; independent component analysis; Phyton programming; power loss; power system simulation network.

\section{INTRODUCTION}

During electricity transmit the power supply from transmission to end user, the effectiveness of the system is controlled by information of the voltage and load in the distribution [4]. The conductors, feeder systems, grounding systems, branch circuits and control equipment are other factors that involved in power distribution system. The electrical power system is distributing the electrical power in three-phase AC current. Transformer is used to increase the $\mathrm{AC}$ voltage level during conversation of electrical power [3]. It is one of the components in power system need to be functioning in the operation. Any failure may give an effect to cost and performance of the system. Transformer is operates to step up or step down the voltages and transfer the power to next substation with different voltage levels. Distribution transformer has primary and secondary windings which are designed to operate at high or low voltages or vice versa.

The line loss $\left(I^{2} R\right)$ is needed to be reduced significantly during transmitting the electricity from generation to first substation. At this condition, the transformer is act as converting from high transmission voltage to voltage level required by customer's need [7]. However, it may have some interruption power loss when delivering the power supply corresponding to the load demand. There are some difficulties to avoid all this interruption especially with a low cost and low maintenance as well. Nevertheless, this research may help the power plant company to reduce their losses during deliver the electricity process using statistically independent algorithm.

Power loss may occur when the voltage level of the system is changes. Hence, the operating transformer tap position and switching shunt capacitors is requires to be maintained for every second. On load tap changer (OLTP) can be installing at primary winding or secondary winding depends on power distribution operating points. The profile of the system may depend on the voltage setting without interrupting the power deliver to the load. Usually, the tap changer will be set once in a time during installation. In [7] use Artificial Neural Network 
(ANN) to control tap changer to supply voltage level and control power sharing of power system. However, in [2] has demonstrated that transformer voltage control is not relevant when the network is connected to Distributed Generator (DG).

Simulating the distribution system is enabling projecting the performance of the future system. This simulation is allows to evaluate the impact of MPI internal implementations. The characteristics of the interconnecting topology can be described by mapping the cluster model. Realistic traffic pattern is generated using real data as input to transaction level model of the system. Most of modeling technique will be giving a high performance of algorithms in order to deliver their best experimental results.

To control power flow system, tap changing need to be well managed as well as adding shunt capacitor banks and shunt reactors. Fig. 1 shows the system branch power flows from sending end voltage (source voltage) to receiving end voltage. The simple model is operating at steady-state conditions. The line impedance of the system consists of inductive impedance and transformer impedance. From this figure, the generator current is

$I=\frac{\mathrm{V}_{\mathrm{s}}<\delta(\mathrm{i})-\mathrm{V}_{\mathrm{R}}<0^{\circ}}{\mathrm{X}_{\mathrm{Z}}+\mathrm{X}_{\mathrm{T}}}$

The complex power delivered by $V_{S}$ is

$S=V I^{*}$

$S=V_{R}\left(\frac{V_{S} e^{-j \delta}-V_{R}}{-j X_{Z}+X_{T}}\right)$

$S=\frac{V_{R} V_{S} e^{-j \delta}-V_{R}{ }^{2}}{-j X_{Z}+X_{T}}$

$S=\frac{V_{R} V_{S}(j \cos \delta+\sin \delta)-j V_{R}^{2}}{X_{Z}+X_{T}}$ 


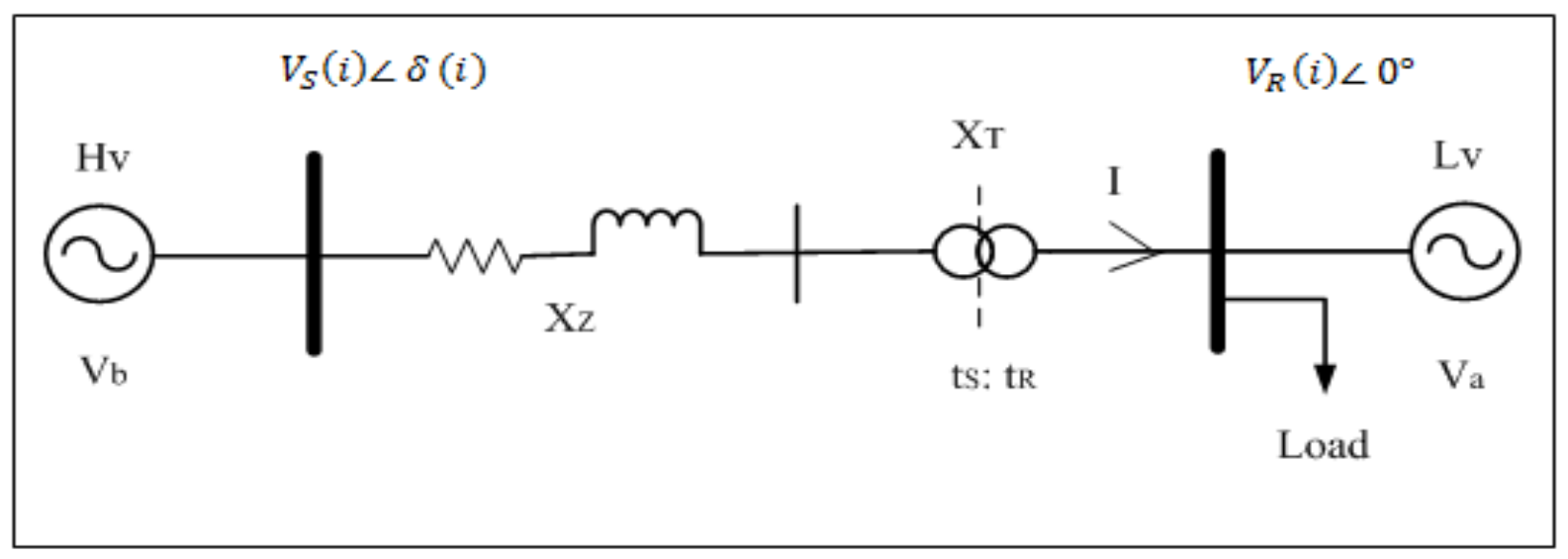

Fig.1. Electric equivalent of system network

Equation (2) is equilibrium with $S=P+j Q$. While, the real and reactive powers delivered are [1].

$P_{R}=\frac{V_{R} V_{S} \sin \delta}{X_{Z}+X_{T}}$

$Q_{R}=\frac{V_{R} V_{S} \cos \delta-V_{R}^{2}}{X_{Z}+X_{T}}=\frac{V_{R}\left(V_{S} \cos \delta-V_{R}\right)}{X_{Z}+X_{T}}$

The impedance in per-unit is given by

$$
X_{p u}=\frac{S_{\text {Base }} \times X_{\text {Actual }}}{V^{2}{ }_{\text {Base }}}
$$

\section{METHODOLOGY}

\subsection{Transformer Tap Changer at Optimal}

Transformer is a device to transform the alternative current and voltage between low voltage and high voltage windings. The power transformer delivers the voltage at constant variable conditions. The variable number of turns on the power transformer can be selected using tap changer. There are two types of tap changer, known as Off Circuit Tap Changer (OCTC) and On Load Tap Changer (OLTC). Transformer tap changers were tested practically to control and restore the voltage without interrupt the maximum power transfer [8]. The system is reliable, stable and under normal loading condition if transformer tap changer is at acceptable range within 0.95 per-unit to 1.05 per-unit [9].

Equation (5) shows that the active power transferred, PR depends on line impedance and the transformer impedance. The higher total line and transformer impedance is the lower power transferred in the system. If the line voltage at high value and the line impedance is fixed, 
therefore the active and reactive power transferred depends to the change in transformer impedance. FromEquation (5), per-unit impedance becomes small and transformer impedance becomes lead at high transmission lines. The transformer impedance can be adjusted by tap changing transformer in order to control active and reactive power. If $V_{S}$ and $V_{R}$ are phase voltage at sending and receiving end bus, therefore:

$V_{S}=V_{R}+I R \cos \theta+I X \sin \theta$

Since active and reactive power at receiving end are $P_{\varphi}=V_{R} I \cos \theta$ and $Q_{\varphi}=V_{R} I \sin \theta$, phase voltage at sending end becomes $[2,3]$ :

$V_{S}=V_{R}+\frac{P_{\varphi} R+Q_{\varphi} X}{V_{R}}$

The equation for supply phase voltage, $V_{a}$ referred to high voltage side, $V_{S}$ is:

$V_{S}=t_{s} V_{a}(8)$

And equation for load phase voltage, $V_{b}$ referred to low voltage side, $V_{R}$ is:

$$
V_{R}=t_{R} V_{b}(9)
$$

Replace Equation (8) and (9) into Equation (7), the equation becomes:

$$
\begin{aligned}
& t_{s} V_{a}=\frac{\left(t_{R} V_{b}\right)^{2}+P_{\varphi} R+Q_{\varphi} X}{t_{R} V_{b}} \\
& t_{s}=\frac{\left(t_{R} V_{b}\right)^{2}+P_{\varphi} R+Q_{\varphi} X}{t_{R} V_{a} V_{b}}(10)
\end{aligned}
$$

However, assume $t_{s} t_{R}=1$.Therefore, tap setting for sending end transformer is:

$t_{s}=\frac{\left[\left(1-t_{s}\right) V_{b}\right]^{2}+P_{\varphi} R+Q_{\varphi} X}{\left(1-t_{s}\right) V_{a} V_{b}}$

$$
t_{s}=\sqrt{\frac{\left(V_{a} / V_{b}\right)}{1-\left(\frac{P_{\varphi} R+Q_{\varphi} X}{V_{a} V_{b}}\right)}}(11)
$$

Theoretically, the voltage regulation can be controlled when the steady state voltage is at acceptable range in transmission line system. Tap changing transformer can be used as equipment to control voltage stability as well as shunt capacitor. The voltage magnitude is increasing when the reactive power is increase at the same bus. It is because there have 
relationship between transmitted $(\mathrm{P})$, injected $(\mathrm{Q})$ and receiving end $(\mathrm{V})$ in order to control stability of the system. The limitation for voltage magnitude is $1.0 \pm 5 \%$ per-unit which is range between 0.95 to 1.05 per-units. System has voltage stability as long as voltage magnitude is under this range. Below than 0.95 per-units indicate that the system has poor voltage magnitude. In this condition, the best tap position within acceptable voltage range is calculated. The calculation is doing by adjusting the tap ratio from 0.80 per-unit to 1.20 per-unit with step size 0.01 and the voltage variable is recorded. In [6] research, the system used in this research was explained. The transmission and distribution network is represented by IEEE 30 and 69 test bus systems.

\subsection{Setting Transformer Tap Changer at 1 Per-Unit}

This section represents 69-test bus system as distribution system tested on two different source setting. The performance of the method is evaluated by comparing losses that occur in distribution system. The transformer is located at line flow from bus 1 to bus 126 when running the integrated network. Tap position in this transformer was set to 1.0 p.u. The voltage profile for source at distribution system was simulated from integrated network. 1-minute load profiles for 24-hour provide 1440 data points are taken in this task.

\subsection{Automation with Phyton}

Python is an interpreter and interactive programming language which is widely used for software development. The design of PSS $^{\text {TME }}$ provides determining the mathematical technique and data base structure flow. It is also called modern simulation on computer hardware which is more constraint. In this thesis, the output result simulated from PSS ${ }^{\text {TME }}$ is then implemented by using Python as automation tool. On the other hand, the power flow solution is simulated by $\mathrm{PSS}^{\mathrm{TM}} \mathrm{E}$ for one instant, while Python is interprete to simulate time series of the power flow solution repetitively [5]. The simulation process for this research can be summarized into Fig. 2. The power flow solution is repetitively simulated for 1440 times which is one minute in 24 hours. 


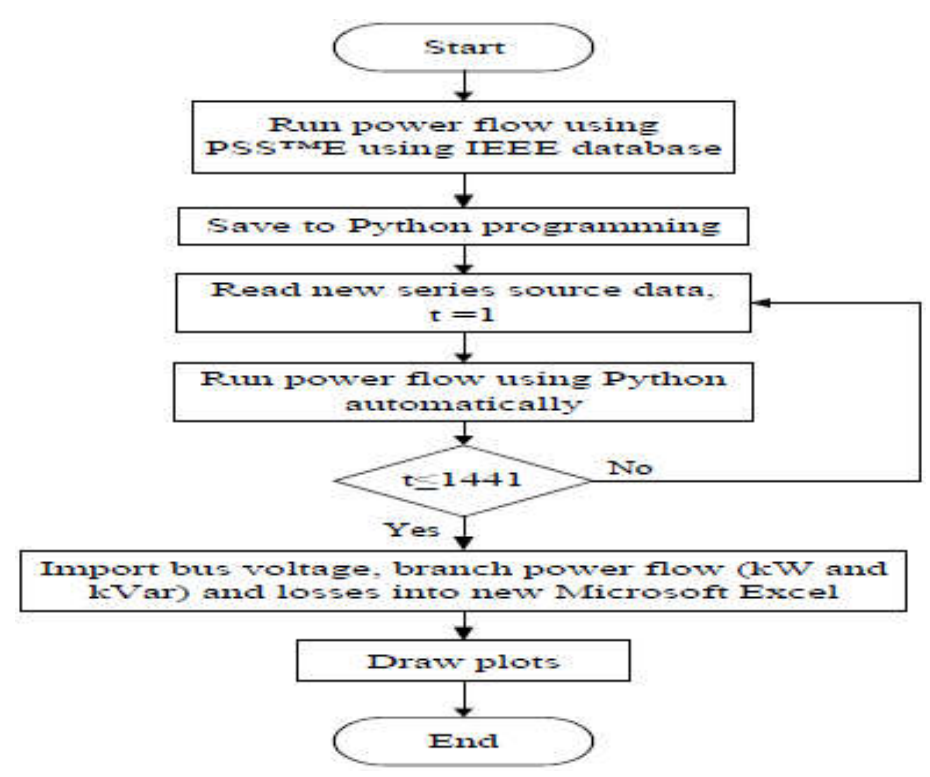

Fig.2. The simulation process for Phython programming

\section{RESULTSAND DISCUSSION}

Table 1 shows the tap position setting at 1.0 per-unit simulated for integrated network on PSSTME software. In this case, tap position is set to 1.0 per-unit placed on Wind 2 Ratio as shown in Table 1. The results on the 69-test bus system for one instant simulation are summarized. From the simulation, the source for distribution area at bus voltage number 1 is $0.9377 \angle-13.53^{\circ}$ per-unit. The transformer nominal rating data is recorded. From bus 1 to bus 126 and from bus 22 to bus 206, the transformer rating 2 is set to 1.0 per-unit. In this simulation, 1 minute data points for 24 -hour period are considered. The total load and losses occur in transmission, distribution and sub-distribution system are summarizedinto Fig. 3, 4 and 5 respectively. 
Table 1. Setting tap position for integrated simulation network on PSS ${ }^{\mathrm{TM}}$ E software simulation

\begin{tabular}{|c|c|c|c|c|c|c|c|c|c|c|}
\hline \multirow{2}{*}{$\begin{array}{c}\text { From Bus } \\
\text { Numbor }\end{array}$} & \multicolumn{2}{|c|}{ From Bus } & \multirow{2}{*}{$\begin{array}{r}\text { To Bus } \\
126\end{array}$} & \multicolumn{2}{|c|}{ To Bus } & \multirow{2}{*}{$\begin{array}{l}\text { Winding } \\
100.0000\end{array}$} & \multirow{2}{*}{\begin{tabular}{|r|} 
V/nd 1 Ratio \\
1.0000
\end{tabular}} & \multirow{2}{*}{$\frac{\text { Wnd 1 }}{0.0000}$} & \multirow{2}{*}{$\begin{array}{c}\text { Wnd 1 } \\
0.00\end{array}$} & \multirow{2}{*}{ Wnd 2 Ratio } \\
\hline & BUSO1 & 1.000 & & BUS 26 & 33.000 & & & & & \\
\hline 2he & 20020 & & 20 & 24008 & -0 & 100.0000 & T.0000 & v.0000 & v.vo & 1.0000 \\
\hline 104 & HANCOCK & 13200 & 112 & HANCOCK & 33.000 & 100.0000 & 0.9320 & 0.0000 & 0.00 & 1.0000 \\
\hline 106 & ROANOKE & 13200 & 109 & ROANOKE & 1.0000 & 100.0000 & 0.9700 & 0.0000 & 0.00 & 1.0000 \\
\hline 106 & ROANOKE & 13200 & 110 & ROANOKE & 33.000 & 100.0000 & 0.9690 & 0.0000 & 0.00 & 1.0000 \\
\hline 109 & ROANOKE & 1.0000 & 110 & ROANOKE & 33.000 & 100.0000 & 1.0000 & 0.0000 & 0.00 & 1.0000 \\
\hline 109 & ROANOKE & 1.0000 & 111 & ROANOKE & 11.000 & 100.0000 & 1.0000 & 0.0000 & 0.00 & 1.0000 \\
\hline 112 & HANCOCK & 33.000 & 113 & HANCOCK & 11.000 & 100.0000 & 1.0000 & 0.0000 & 0.00 & 1.0000 \\
\hline 127 & CLOVERDL & 33.00 & 128 & CLOVERDL & 132.0 & 100.0000 & 1.0000 & 0.0000 & 0.00 & 0.9680 \\
\hline
\end{tabular}

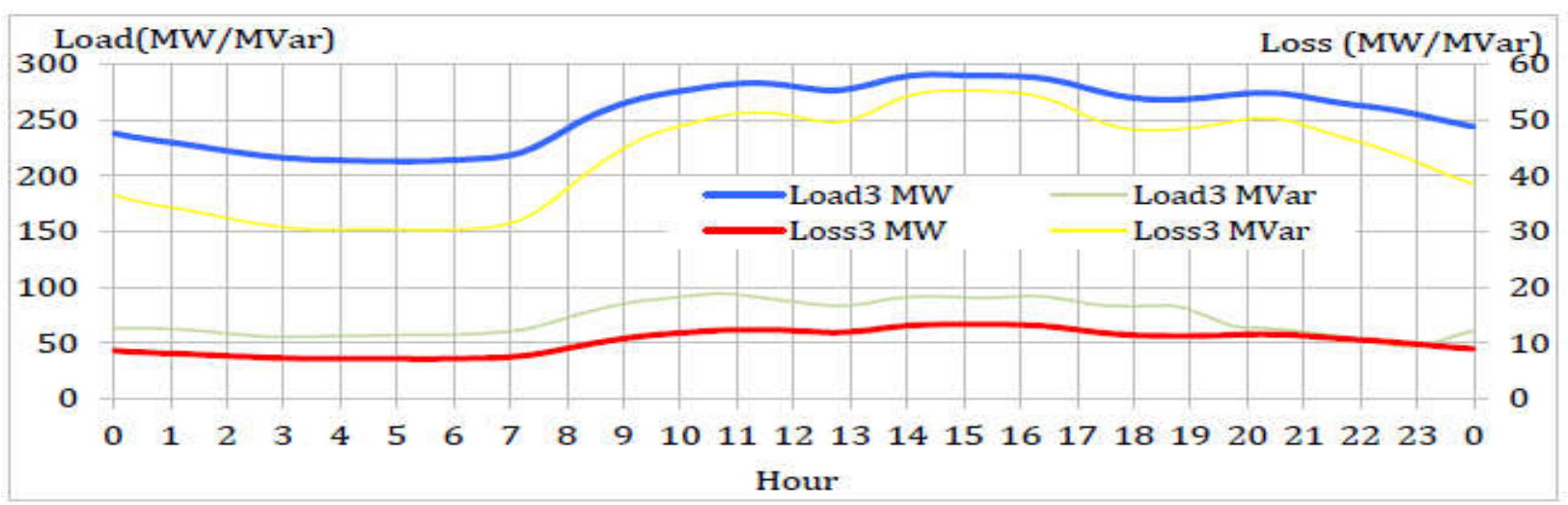

Fig.3.Total load and loss occur at transmission system (tap position at 1.0 p.u for 69-test bus system)

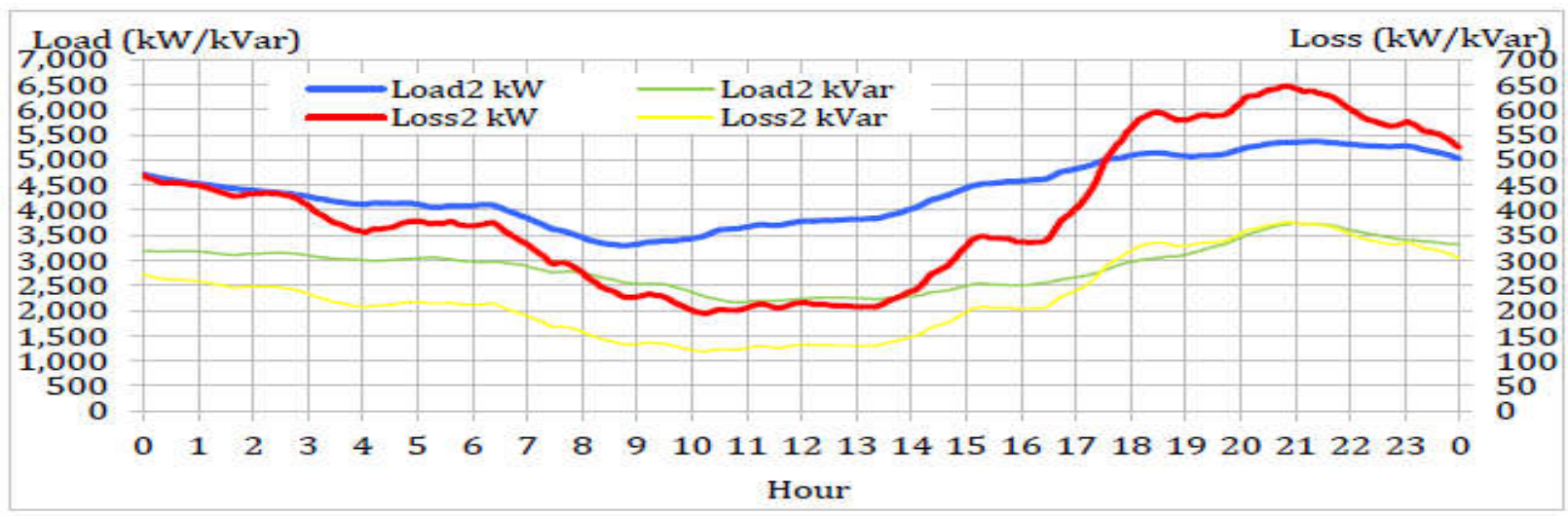

Fig.4.Total load and loss occur at distribution system (tap position at 1.0 p.u for 69-test bus system) 


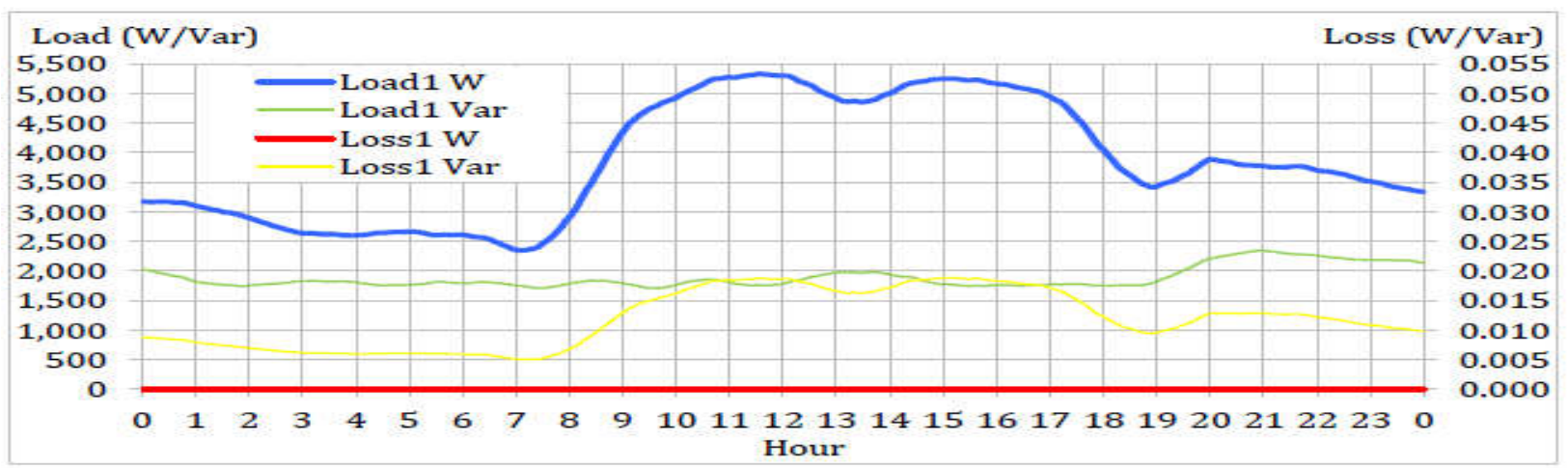

Fig.5.Total load and loss occur at sub-distribution system (tap position at 1.0 p.u for 69-test bus system)

The calculation is doing by adjusting the tap ratio from 0.80 per-unit to 1.20 per-unit with step size 0.01 and the voltage variable was recorded into Fig. 6 . Both of these figures describe that voltage variation is varying with tap position in the system. It is seen that at maximum voltage per-unit, the tap position at optimal is 1.0858 per-unit when tested on 69 bus system. The total loss reducing is when voltage at interface increased to 1.05 per-unit. Tap changer at 1.0858 per-unit is applied to simulate the integrated circuit when considering the transformer tap position at optimal. The integrated simulation result when set transformer tap position at optimal value is shown in Table 2. Bus number 1 at 69 -test bus system has bus voltage of $1.0185 \angle-13.51^{\circ}$ per-unit. The transformer nominal rating from bus 1 to bus 126 is 1.0858 per-units and from bus 22 to bus 206 is 1.0 per-unit. Fig. 7, 8 and 9 represent total load and total losses occur in transmission, distribution and sub-distribution system respectively. 


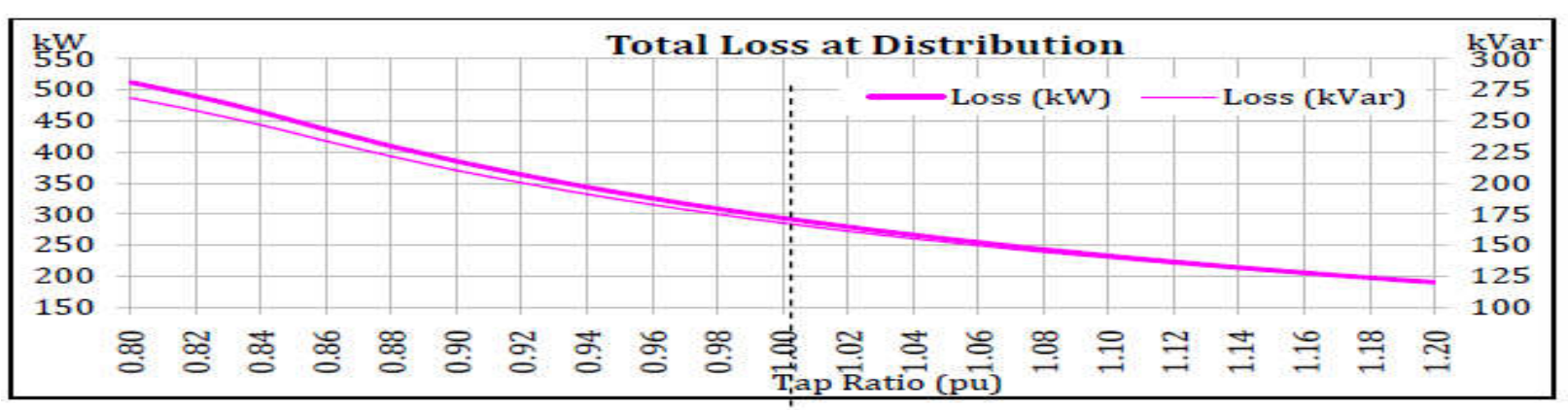

Total Loss Occur At 69 Bus Distribution System

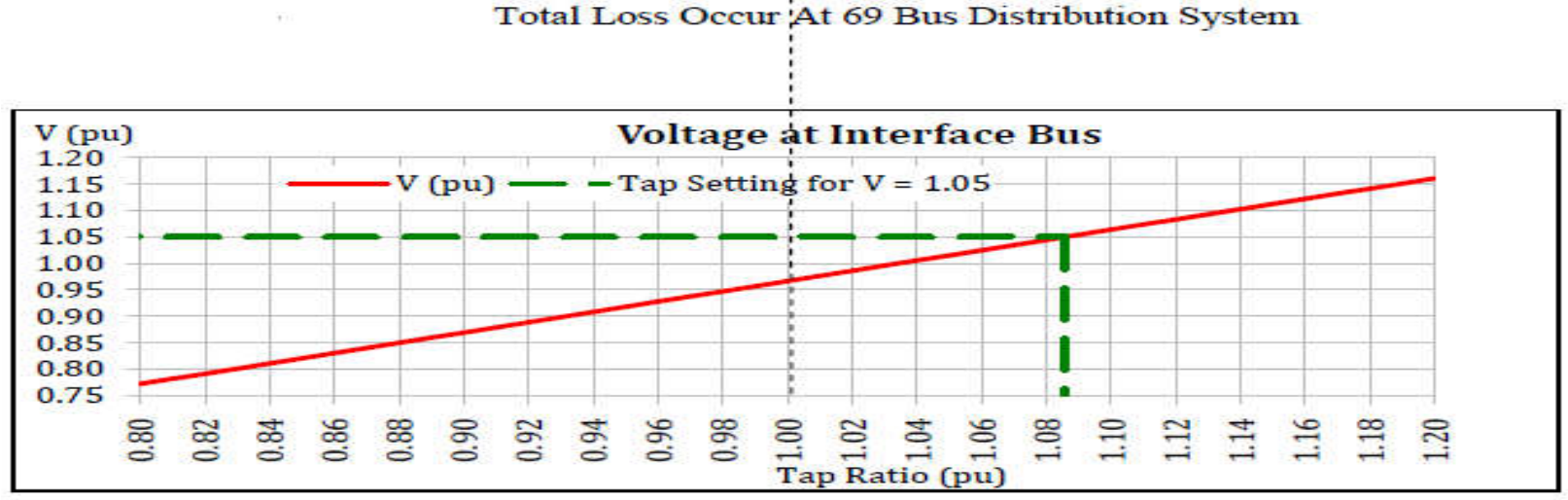

Source Voltage Changing Varies With Tap Ratio Tested On 69 Bus Distribution Systems

Fig.6. The result of setting tap changer repetitively

Table 2. Setting tap position at 1.0858 per-unit in PSS ${ }^{\text {TME }}$ software

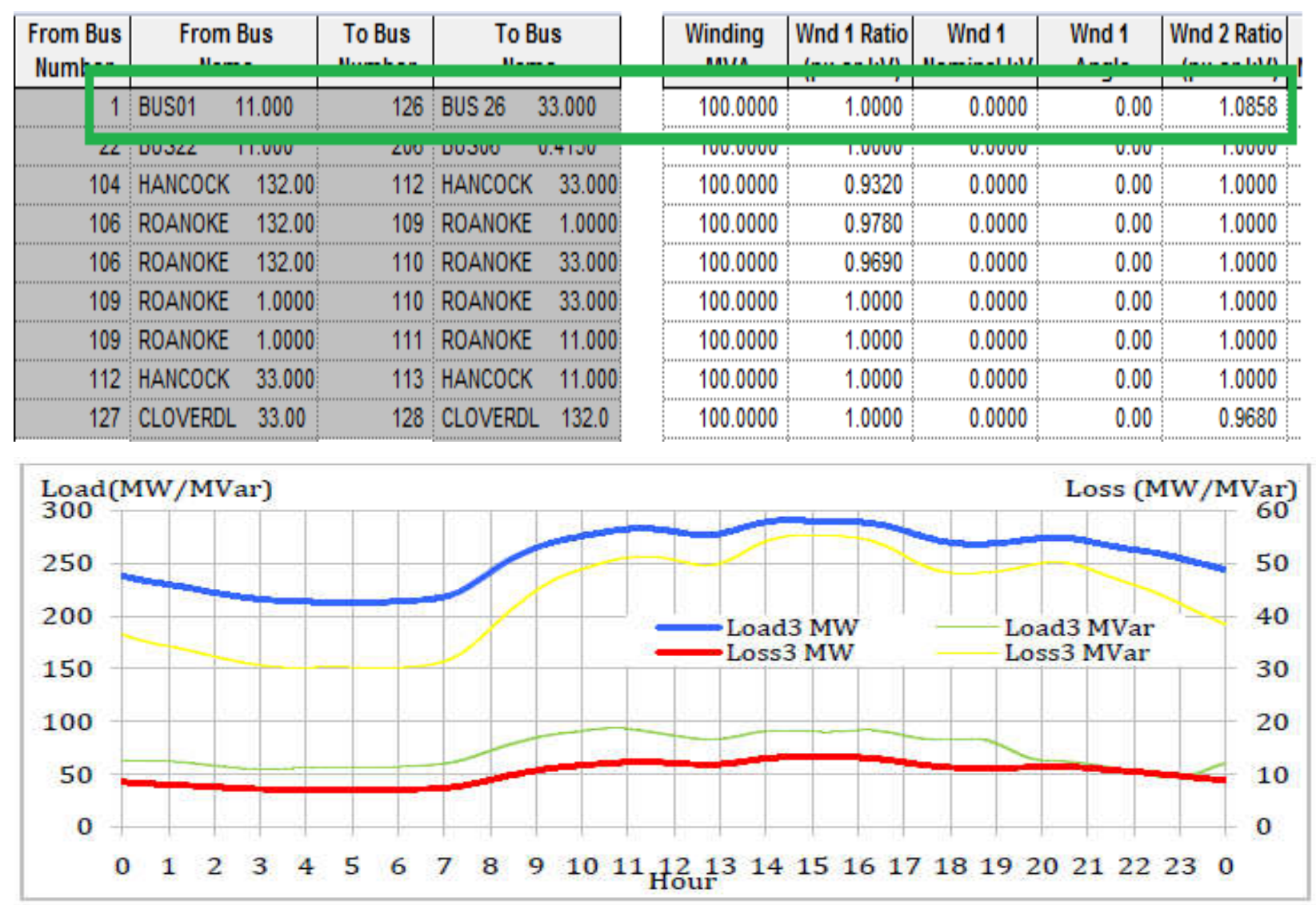

Fig.7. Total load and loss occur at transmission system (tap position at optimal for 69-test bus 
system)

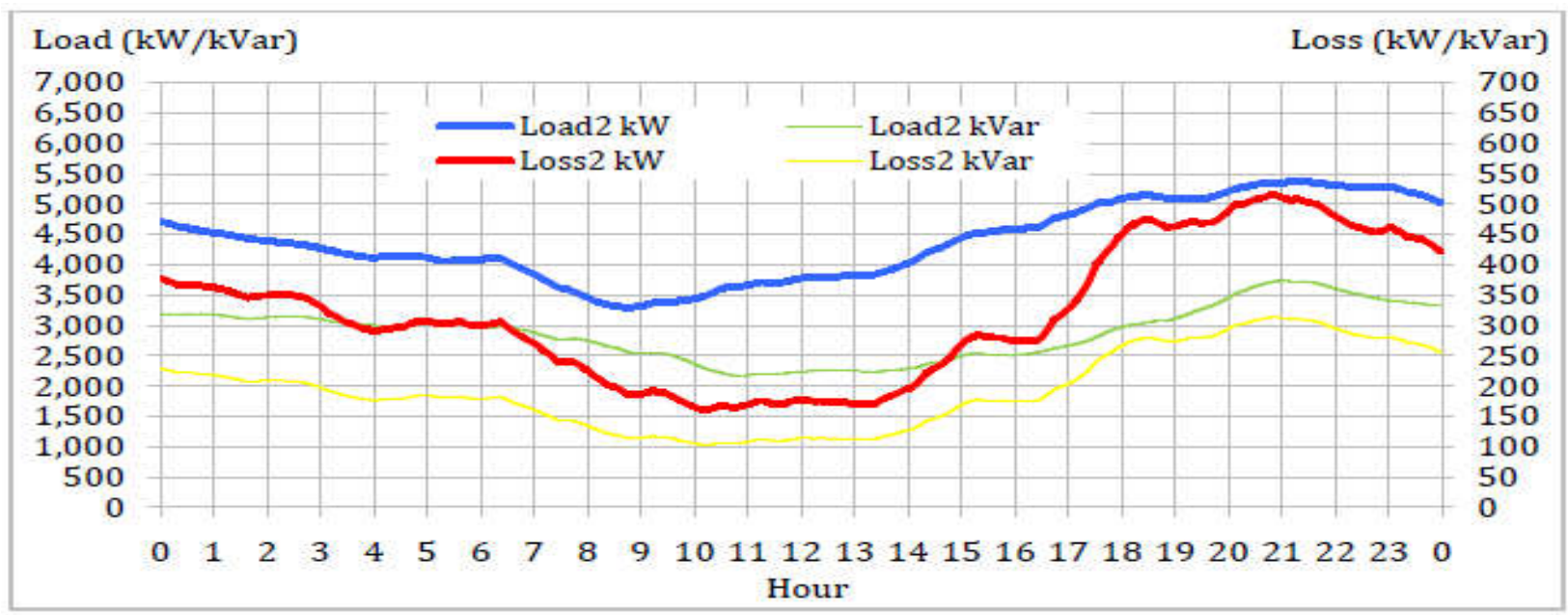

Fig.8. Total load and loss occur at distribution system (tap position at optimal for 69-test bus system)

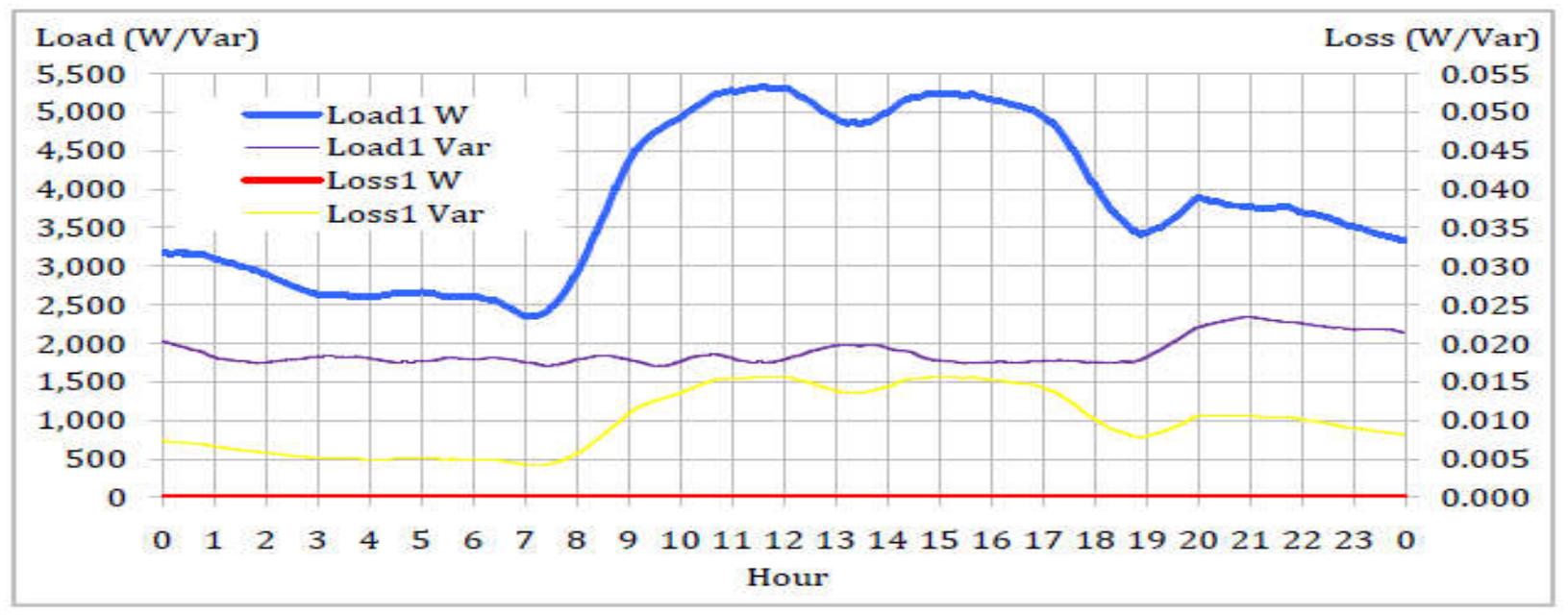

Fig.9. Total load and loss occur at sub-distribution system (tap position at optimal for 69-test bus system)

\section{ACKNOWLEDGEMENTS}

This work was supported by Fundamental Research Grant Scheme (FRGS) No: 600-RMI/FRGS 5/3 (143/2015) awarded by Ministry of Higher Education (MOHE) Malaysia. The authors also thanked to Institute of Research Management and Innovation (IRMI), UniversitiTeknologi MARA (UiTM), Shah Alam, Selangor, Malaysia for the support given in this research. 


\section{CONCLUSION}

In conclusion, it is seen that the total load profile on distribution system is remain the same when setting tap transformer at 1.0 p.u and optimal setting as shown in Fig. 3 and Fig. 7. However, the losses at distribution is decreased around $100 \mathrm{~kW}$ when the transformer at optimal compare to transformer at 1.0 p.u. Tap changer is a best method to control voltage stability limit and reduce total power loss [1] compared to adding shunt capacitor method in transmission network. Tap changer used to regulate the voltage level on power delivery system. On the other hands, voltage limits can be maintained using tap changer by adding or reduce number of winding turns. Number of turns is connected or disconnected from winding. When increase number of turns in the circuit, the voltage level at interface becomes high. Hence, the impedance of transformer changes during the number of turns changes via tap changer.

\section{REFERENCES}

[1] Dahalan W M, Othman A G, Zoolfakar M R, Khalid P Z M, Rizman Z I. Optimum DNR and DG sizing for power loss reduction using improved meta-heuristic methods. ARPN Journal of Engineering and Applied Sciences, 2006, 11(20):11925-11929

[2] Gao C, Redfern M A. Advanced voltage control strategy for on-load tap-changer transformers with distributed generations. In 46th InternationalUniversities' Power Engineering Conference, 2011, pp. 1-6

[3] Halpin, S M, Grigsby L L. Single-phase power distribution system power flow and fault analysis. IEEE Transactions on Aerospace and Electronic Systems, 1992, 28(4):1033-1041

[4] Hussain M M, Serwan S, Zakaria Z H. Nodal load profiles estimation for time series load flow using independent component analysis. International Journal of Electrical, Computer, Energetic, Electronic and Communication Engineering, 2012, 6:1437-1442

[5] Hussain M M, Zakaria Z H, Serwan S. FastICA techniques for load profiles estimation. In IEEE Symposium on Industrial Electronics and Applications, 2012, pp. 161-166

[6] Hussain M M, Zakaria Z H, Serwan S. Voltage estimation using ICA on distribution system. In 7th IEEE Power Engineering and Optimization Conference, 2013, pp. 267-272 
[7] Islam M F, Kamruzzaman J, Lu G. Transformer tap changing by data classification using artificial neural network. In IEEE Power Systems Conference and Exposition, 2004, pp. $1417-1422$

[8] Swe P L, Swe W, Lin K M. Effects of tap changing transformer and shunt capacitor on voltage stability enhancement of transmission networks. Journal of World Academy of Science, Engineering and Technology, 2011, 5:555558

[9] Yang K, Garba A, Tan C S, Lo K L. The impact of the wind generation on reactive power requirement and voltage profile. In 3rd IEEE International Conference onElectric Utility Deregulation and Restructuring and Power Technologies, 2008, pp. 866-871

\section{How to cite this article:}

Hussain M M, Zakaria Z, Rizman Z I, Yasin M A M. Power loss estimation due to difference transformer tap changer position at interface. J. Fundam. Appl. Sci., 2017, 9(3S), 685-696 